Jérémy Hervelin*

\title{
Directing young dropouts via SMS: evidence from a field experiment
}

\begin{abstract}
Although short message services (SMS) are constantly used to transmit information, little is known about the use of SMS by public institutions to direct people. This paper presents a field experiment in France about the effectiveness of SMS in directing disadvantaged people toward public services. Two types of treatment SMS were provided: one type had its content written in a formal style; the second type SMS style was much informal. All the SMS were individualized and included specific information about the agencies. Results indicate that the SMS had no significant effect on enrollment. There is also no apparent heterogeneous effect according to individual, agency, or location characteristics. In line with other academic evidence, these findings suggest that SMS have very limited effectiveness in directing this population toward public services.
\end{abstract}

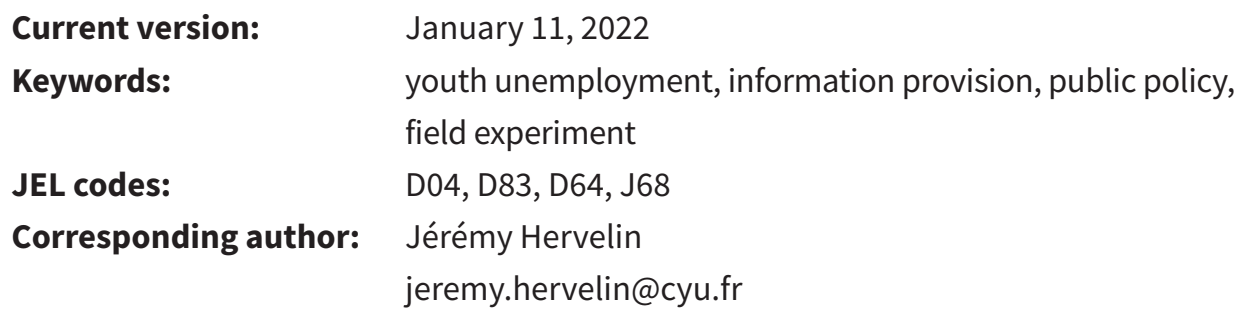

THEMA Research Center, CY Cergy Paris University, 33 Boulevard du Port, Cergy-Pontoise 95000, France

(c) The Author(s). 2022 Open Access This article is distributed under the terms of the Creative Commons Attribution 4.0 International License (http://creativecommons.org/licenses/by/4.0/), which permits unrestricted use, distribution, and reproduction in any medium, provided you give appropriate credit to the original author(s) and the source, provide a link to the Creative Commons license, and indicate if changes were made. @ Cite as: Hervelin. IZA Journal of Labor Policy (2022) 12:01. 


\section{Introduction}

Recent empirical evidence shows that planned and assisted job search strategies are effective for young job seekers trying to find employment (Abel et al., 2019; Belot et al., 2019). Yet, many countries face hard times identifying young school dropouts and directing them to public agencies through which they can receive such assistance. ${ }^{1}$ This fact raises questions about how institutions communicate and suggests that they should consider other ways of communicating so as to enroll greater numbers.

Nowadays, most individuals communicate through SMS daily. ${ }^{2}$ Whether SMS are sent to relatives to maintain relationships (Ling, 2010), by private firms to sell their goods (Rettie et al., 2005), or by medical centers to sustain individuals' efforts in combating substance abuse (Mason et al., 2015), SMS seem to be a low-cost effective channel of communication for transmitting information. Accordingly, we analyze whether SMS might be an appropriate solution for public assistance agencies to direct young dropouts?

The style adopted in the SMS seems to matter, especially for young people. Some studies show that texts addressed to young people should be carefully analyzed if they are to provide them with better advice about education-, health-, or life- related choices (Hudson et al., 2012; Graham, 2013; Ehrenreich et al., 2014). For instance, the US firm American Telephone \& Telegraph Company (AT\&T) saw an increase in positive reactions from young people after broadcasting a series of television commercials in which the protagonists spoke like young people's text messages (Jones and Schieffelin, 2009). Accordingly, if public assistance agencies were to adopt an informal language for their communication, would they be more effective in directing young dropouts?

This paper is the first to address these two questions in the field by sending SMS randomly, with either formal or informal content, to direct young dropouts who are not in employment, education, or training (NEET) toward public assistance agencies in France.

\section{Related Literature}

This paper mostly contributes to the literature on program take-up through the provision of information. In the United States, some studies find positive effects on disability insurance take-up (Armour, 2018), on the demand for tax credits (Bhargava and Manoli, 2015), on social security subscription (Finkelstein and Notowidigdo, 2019), on voting for political elections (Gerber et al., 2008), and on labor force participation from letters correcting misconceptions about social security earnings (Liebman and Luttmer, 2015). Barr and Turner (2018) find a positive effect on higher education enrollment from letters pointing out the benefits of training for displaced workers after the financial crisis. Bettinger et al. (2012) find positive effects on college enrollment of American high school students by assisting them throughout the application process. In Canada, Oreopoulos and Dunn (2013) find that online information and video tutorials increase the willingness of high school students to pursue higher education. In Germany, Berkes et al. (2019) find positive effects in terms of improving graduate students' beliefs about the benefits of graduation returns by providing online information via an

1 See, for instance, the Organisation for Economic Co-operation and Development (OECD) collection Investing in Youth.

2 I use the terms SMS, texts, text messages, or text messaging as synonyms throughout the whole paper. 
interactive survey. Altmann et al. (2018) find a positive effect on exit from unemployment from an information brochure pointing out the harm of being unemployed and suggesting strategies for a return to job-seeking, but only among long-term high-risk unemployed job seekers. In France, Goldzahl et al. (2018) find no effect from information letters related to breast-cancer screening uptake, which describe the risks of this form of cancer and suggest a free-of-charge service with a voucher. However, it is difficult to disentangle the effect of the information itself from the channel through which it is delivered in those papers, especially for those that involve several communication media or multiple information content over time. In the present study, young dropouts received simple SMS - whose language style is either formal or informal directing toward local public agencies delivering job search assistance programs. It concludes that sending SMS, whatever style is adopted, does not increase the number of young dropouts enrolled in those agencies.

The remainder of the paper is organized as follows. Section 2 presents the relevant French institutions and some characteristics of young dropouts. Section 3 describes the experimental design. Section 4 shows the results of the experiment. Section 5 concludes the paper.

\section{Background}

All French youths are required to remain in the education system until the age of 16 years. While at school, they start a citizenship pathway built on three compulsory stages. The first stage concerns classes related to national defense, all during the 9th and 11th grades. The second involves registering at the town hall at most 3 months after the 16th birthday. The third stage is the army day, called "La Journée Défense et Citoyenneté" (JDC).

Young people attend the army day once after receiving an official invitation from the Ministry of the Army. Attendance is required by law when taking any diploma or competitive exam under the control of the public authority at $<25$ years of age. Army days have taken place every year at different military centers since 1998. About 40-50 young people attend a given army day at a specific military center. The army day agenda is set between 8:30 am and 5:00 pm. At the beginning of the day, all participants must fill in a form pertaining to their situation with respect to schooling or the labor market. They take a 30-min test before lunch to assess their proficiency in French. During the remainder of the day, military instructors aim to raise the participants' awareness of national security and other social issues, such as drug abuse, road safety, racism, and so on. They also inform participants about public institutions that supply active labor market programs.

Every year, about 800,000 young people participate in army days. According to a report from the French general accounting office, 96\%-98\% of all French-born individuals do their army day before they turn 25 years old (Cour des Comptes, 2016). Information filled by youth at the beginning of the army day is recorded by military men in an information system called the "Système d'aide à la gestion des administrés" (SAGA). This database is primarily used as an up-to-date census of French people who could be called up in wartime.

Table 1 shows the aggregated values of some characteristics averaged over the period January 2013-July 2019. Information on all youths who attended the army day is shown in Column (1), while Column (2) restricts the sample to school dropouts. It appears that dropouts are more often males, do their army day more often when older, more often have an educational 
Table 1 Descriptive statistics of all youths and dropouts during army days

\begin{tabular}{lcc}
\hline Characteristics & \% of all youths & \% of all dropouts \\
\cline { 2 - 3 } & $\mathbf{( 1 )}$ & $\mathbf{( 2 )}$ \\
\hline Gender (male) & 51.11 & 61.15 \\
Age & & \\
16-17 years old & 95.55 & 75.24 \\
18-21 years old & 3.85 & 21.14 \\
22-25 years old & 0.60 & 3.62 \\
School & & \\
Lower secondary & 83.95 & 99.77 \\
Vocational upper secondary & 10.58 & 0.21 \\
General upper secondary & 5.05 & 0.02 \\
Postsecondary & 0.42 & 0.00 \\
Literacy & & 64.72 \\
Level A & 88.44 & 13.23 \\
Level B & 2.99 & 5.62 \\
Level C & 1.87 & 8.56 \\
Level D & 2.66 & 7.04 \\
Level E & 3.27 & 63.49 \\
Directed & & 32.46 \\
Toward any partner public institution & 11.79 & 237,110 \\
Toward ML agencies & 2.19 & \\
Total number of observations & $5,514,495$ & \\
\hline
\end{tabular}

Notes: This table reports descriptive statistics about some characteristics of youths and dropouts during army days. "Age" is age at the army day. The category "School" for dropouts corresponds to the level at which youths drop out of the school system. "Level A" for "Literacy" corresponds to "normal literacy", while "Level E" corresponds to "illiteracy" and Levels $B-D$ range for decreasing levels of medium literacy. Partner public institutions of army days include Établissement pour l'insertion dans l'emploi (EPIDE), Service militaire adapté (SMA), Centres d'informations et d'orientation (CIO), Savoirs pour réussir (SPR), and the MLs.

Source: SAGA 2013-2019 database, author calculations.

MLs, missions locales; SAGA, Système d'aide à la gestion des administrés.

level equivalent to middle school, are less proficient in French, and are more directed toward a partner institution that supplies mostly active labor market programs.

Among them, the mission locale (ML) agencies comprise a network of French institutions dedicated to dealing with 16 - to 25 -year-old youths who potentially face problems in relation to employment, health, housing, transport, psychology, and so on. There are about 440 agencies spread over the whole territory and 13,000 caseworkers performing individual or collective meetings. At the local level, each agency is free to publicize its service through an appropriate medium. Agencies may variously put up posters on walls, communicate through social media, participate in school or business meetings, and so on. However, there is no record or follow-up about the effects of such attempts. At the national level, the main call for young people to join is made by military instructors during the army days. Table 1 shows that about one third of the dropouts are directed to an agency.

It is only possible to verify whether directing the youths was successful by merging SAGA together with the information system of the agencies called Informations Missions Locales (IMILO). Table A1 in Online Appendix A shows that the effect of military guidance is positive 
when controlling for individual characteristics and month fixed effects. Military men increase the enrollment rate of young dropouts in public agencies by about 8 percentage points (pp) on average, which corresponds to an increase of approximately $17 \%$. This result is thus driven by selection effects and cannot be interpreted as causal. The experiment presented in the section aims to analyze the probability of going to such public agencies following the receipt of an SMS.

\section{Field Experiment}

The experiment involved sending two SMS to youths identified as dropouts during army days to direct them to the nearest ML public agency.

Dropouts were randomly allocated to one of three groups. One fifth of the dropouts did not receive SMS and thus constituted the control group. Another fifth made up the first treated group and received SMS, with formal language and content giving the name and the postal address of the nearest agency. The remaining three fifths were allocated to a second treatment group, with more informal language and subdivided according to an additional specific piece of information. All the second subtreatment groups received the same basic information as the first treated group and additionally received information about the distance in kilometers, the past enrollment rate, or both. Full texts related to each group are shown in Table 2. ${ }^{3}$ All SMS were sent twice, the second serving as a reminder.

SMS sent in the first treatment are similar to typical texts sent by some public agencies, with whom the design of the messages was discussed. It contains basic information (name and location of the agency) and no particular design for the text content. In contrast, SMS in the second treatment group added content on the basis of literature in psychology and brain science with the hope of better matching the way young people communicate. Jones and Schieffelin (2009) note that young people communicate through texting in a way that differs from the standard forms of speaking and writing, by playing with words, grammar, and so on. Though structurally equivalent to the SMS in Treatment 1 for statistical comparisons, the SMS in Treatment 2 include specific elements, such as an informal tone or a smiley associated with positive

Table 2 Control and treatment groups

\begin{tabular}{|c|c|}
\hline Group & Name \\
\hline Control & No SMS \\
\hline Treatment 1 & SMS - formal style \\
\hline \multicolumn{2}{|c|}{$\begin{array}{l}\text { HELLO \{YOUTH FIRSTNAME\}, THE \{AGENCY NAME\} ADVISES YOUTHS ON THEIR PROJECTS. MORE } \\
\text { INFORMATION AT \{AGENCY ADDRESS\}. THE } 1^{\text {ST }} \text { MEETING DOES NOT REQUIRE AN APPOINTMENT. }\end{array}$} \\
\hline Treatment 2 & SMS - informal style \\
\hline $\begin{array}{l}\text { HEY \{YOUTH } \\
<\text { SPECIFIC IN } \\
\text { REQUIREAN }\end{array}$ & $\begin{array}{l}\text { E\} ADVISES YOUTHS ON THEIR PROJECTS. + } \\
\text { AGENCY ADDRESS\}. THE } 1^{\text {ST }} \text { MEETING DOES NOT }\end{array}$ \\
\hline
\end{tabular}

Notes: This table reports the different groups in which young dropouts were allocated during the experiment and the content of the text they received. Elements in curly brackets are variables that changed according to individual name and location.

3 Table B1 in Online Appendix B shows the text content in the original version, and Figure B1 shows how they are displayed on a smartphone screen. 
emotions when referring to oneself or undertaking actions after reading the texts. ${ }^{4}$ Riordan and Kreuz (2010) and Ling and Baron (2016) show that computer-mediated-communication (CMC) includes peculiar cues that differ from those used in face-to-face (F2F) communication. For instance, emoticons are an important part of texts because they allow individuals to mimic different facial expressions that cannot be easily displayed in CMC. All the elements describing the SMS are presented in more detail in Online Appendix C.

The experiment includes youths who did their army day between January 1, 2019 and May 31, 2019. Two conditions were needed to be satisfied in making the selection:

- The youth was a dropout and had never attended an ML agency;

- A valid mobile phone number was provided to properly deliver the SMS. ${ }^{5}$

I used SAGA and IMILO databases to carry out the experiment. Both databases are updated monthly with a 1-monthlag, i.e., the SAGA database of February 2019 included all youths who did their army day up to January 31 . The same applies for IMILO. After obtaining a copy of the two databases, I cleaned the information related to personal records (last name + first name + gender + date of birth + place of birth). Once the two databases were cleaned, I extracted the sample by merging them on names, using the Jaro-Wrinkler distance algorithm and exact matching on gender, date of birth, and place of birth. The output file listed dropouts who had never registered with an agency.

The next task was to assign a particular agency to each youth. Agencies accept youths who live in the same geographical area, generally at the commuting zone level. Otherwise, they redirect them to the appropriate agency. Since the postal addresses of both youths and the agencies were available in the database, I assigned the agency located nearest to each individual, based on the geodesic distance algorithm, provided it was in the same geographical unit.

In total, 4,457 youths participated in the experiment, and 3,540 youths were contacted from March 6, 2019 to July 17, 2019. ${ }^{6}$ Figure D1 in Online Appendix D shows the minimum effect I can detect given the sample sizes. The experiment allows the detection of a minimum effect of between $\pm 3 \mathrm{pp}$ and $\pm 6 \mathrm{pp}$ at the $5 \%$ significance level, considering a power of $80 \%$, when pooling all the SMS together in comparison with the control group (no SMS).

\section{Results and Discussion}

Table E1 in Online Appendix E shows that the randomization process was successful. Therefore, I estimate the following linear probability model with ordinary least squares (OLS) estimators to analyze the effect of the SMS:

$$
y_{i j}=\alpha+\beta_{k} S M S_{i=k}+X^{\prime} \gamma+\epsilon_{i j} \#
$$

where $y_{i j}$ is a dummy variable equal to one if youth $i$ went to the ML agency $j$, zero otherwise. $S M S_{i=k}$ is a dummy variable equal to one if youth $i$ received SMS $k \in\{$ Formal; Informal $\}$, zero

4 The dissimilarity between the SMS in Treatment 1 and Treatment 2 and the informal tone are far more perceptible in the original version in French than in English because of the difference implied by the tutoiement ("tu") and vouvoiement ("vous"), which does not exist in English (only "you"). See Table B1 in Online Appendix B and Table C1 in Appendix C for more details.

5 About $70 \%$ of the participants provided a valid mobile number. This sample is similar to the whole sample based on the available characteristics provided in SAGA.

6 The SMS sender's name was restricted to eight characters by the digital platform (twilio.org) and set to "INFOS ML" for "Informations Missions Locales". 
otherwise. $X$ is a vector of control variables including information displayed in the text, individual characteristics, agency characteristics, location characteristics, and month fixed effects. $\epsilon_{i j}$ is a residual term, orthogonal to treatment variables because of randomization. Turning to parameters, $\beta_{k}$ is of interest and measures the intention-to-treat (ITT) effects, i.e., the differential in probabilities of going to an agency in comparison to the control group (which receive no SMS at all) with a group receiving SMS of type $k$. The OLS estimates of $\beta$ are reported in Table 3 .

Table 3 ITT effects

\begin{tabular}{|c|c|c|c|c|c|c|}
\hline \multirow[t]{2}{*}{ OLS estimates } & \multicolumn{6}{|c|}{ Entry in agency (0/1) } \\
\hline & (1) & (2) & (3) & (4) & (5) & (6) \\
\hline \multicolumn{7}{|l|}{ Panel A: impact of SMS } \\
\hline \multirow[t]{2}{*}{ SMS - all } & -0.0097 & -0.0100 & -0.0092 & -0.0090 & -0.0091 & -0.0093 \\
\hline & $(0.0143)$ & $(0.0144)$ & $(0.0152)$ & $(0.0154)$ & $(0.0160)$ & $(0.0162)$ \\
\hline \multirow[t]{2}{*}{ Constant (reference: no SMS) } & $0.1864^{\star \star \star}$ & $0.1866^{\star \star \star}$ & $0.1860^{\star \star \star}$ & $0.1858^{\star \star \star}$ & $0.1859^{\star \star \star}$ & $0.1860^{\star \star \star}$ \\
\hline & $(0.0146)$ & $(0.0146)$ & $(0.0159)$ & $(0.0160)$ & $(0.0166)$ & $(0.0130)$ \\
\hline \multicolumn{7}{|c|}{ Panel B: impact of SMS according to language style } \\
\hline \multirow[t]{2}{*}{ SMS - formal } & -0.0003 & -0.0000 & 0.0016 & 0.0020 & 0.0026 & 0.0019 \\
\hline & $(0.0165)$ & $(0.0168)$ & $(0.0170)$ & $(0.0174)$ & $(0.0179)$ & $(0.0181)$ \\
\hline \multirow[t]{2}{*}{ SMS - informal } & -0.0129 & -0.0134 & -0.0129 & -0.0128 & -0.0131 & -0.0131 \\
\hline & $(0.0143)$ & $(0.0143)$ & $(0.0153)$ & $(0.0155)$ & $(0.0161)$ & $(0.0163)$ \\
\hline \multirow[t]{2}{*}{ Constant (reference: no SMS) } & $0.1864^{* \star *}$ & $0.1866^{* \star *}$ & $0.1860^{\star \star \star}$ & $0.1859^{* \star *}$ & $0.1859^{* * *}$ & $0.1861^{* \star \star}$ \\
\hline & $(0.0146)$ & $(0.0146)$ & $(0.0159)$ & $(0.0160)$ & $(0.0166)$ & $(0.0130)$ \\
\hline$\beta_{\mathrm{SMS} \mathrm{Formal}}=\beta_{\mathrm{SMS} \text { Informal }}$ & 0.1599 & 0.1314 & 0.1099 & 0.1107 & 0.0957 & 0.1020 \\
\hline $\mathrm{N}$ & 4,103 & 4,103 & 4,103 & 4,103 & 4,103 & 4,103 \\
\hline Displayed information & No & Yes & Yes & Yes & Yes & Yes \\
\hline Individual characteristics & No & No & Yes & Yes & Yes & Yes \\
\hline Agency characteristics & No & No & No & Yes & Yes & Yes \\
\hline Location characteristics & No & No & No & No & Yes & Yes \\
\hline Month fixed effects & No & No & No & No & No & Yes \\
\hline
\end{tabular}

Notes: This table reports OLS estimates, where the dependent variable is a dummy variable equal to one if the individual went to an ML agency after its army day, zero otherwise. "SMS - X" are dummy variables equal to one if the individual received a specific treatment SMS, zero otherwise. Displayed information corresponds to variables that might have been displayed in the different treatment texts as the distance (in kilometers) to the agency and the number of youths enrolled in the agency on the month before the army day. Individual characteristics include dummies for gender, birthplace, age at the army day, literacy level, and region of residency. Agency characteristics include dummies for the number of agencies, number of committee rooms, number of points of contacts, number of firms in portfolio, number of caseworkers, mean age of caseworkers, share of male caseworkers, and average number of caseloads per caseworker. Location characteristics include dummies for disadvantaged area, type of city, local unemployment rate, the number of services, number of stores, number of schools, number of transport modes, and number of leisure facilities. All the control variables are introduced as dummy variables that have been demeaned so as to leave the constant mostly unchanged, as suggested in Athey and Imbens (2017). The estimations include 4,103 observations instead of the full sample of 4,457 because some agency and location characteristics are missing for about 400 observations. Estimates are equivalent whether these individuals are included or not. Robust standard errors are clustered at the month of the army day level and are reported below the coefficients in parentheses. The line $\beta_{\text {Formal }}=\beta_{\text {Informal }}$ reports the $p$-values associated with a Student test of equality of the SMS estimates.

*** Significant at $1 \%$.

ITT, intention-to-treat; ML, mission locale; OLS, ordinary least squares. 


\subsection{The overall effect of SMS}

I start the analysis by pooling all the SMS together to assess their overall impact and bring answers related to the first question asked in the Introduction section.

Results are shown in Panel A of Table 3. Column (1) reports the estimates without control variables as the baseline estimation, while Columns (2)-(6) introduce all the covariates progressively. The results (which are stable across specifications), ranging around $-1 \mathrm{pp}$, show the absence of statistically significant effects of SMS on the probability of going to an ML agency. ${ }^{8}$ Panel A of Table F1 in Online Appendix F shows the same results with nonlinear probit estimates.

Considering the job search theory, job seekers would not go to a public agency because the associated benefits do not exceed the associated cost or because the net value of assistance they provide is below those of outside options. It can be thus rational for young dropouts to not ask for public assistance if the returns from public agencies are not sufficient.

Very little information on agencies' performances is available online. Young people make expectations on the net value of assistance in the context of this situation. If those expectations are correct, then none of the communication mediums will be effective in directing more young dropouts.

The objective of the SMS was to indicate the presence of a public agency located nearest to the young dropouts, in the simplest way at an almost-zero cost, and increase their enrollment rate. Information provided in the SMS (the location, time distance, or past enrollment levels) could have been irrelevant for this population, or the lapse of time between the army days and the SMS was too long in practice - 50 days on average. However, the few recent field experiments related to SMS yield also contrasting results. In the United States, Castleman and Page (2015) detect a positive effect of about $10 \%$ on higher education enrollment from sending a series of SMS to high school students during summertime, to counteract a potential drop in motivation. The effects were positive only for students who had no existing plans after high school. Fryer (2016) finds no effect on grades from supportive SMS for high school students when they are provided with free mobile phones and texts sent daily. Oreopoulos and Petronijevic (2019) and Oreopoulos et al. (2020) also find no effect from coaching text messages on the academic performance of students at the University of Toronto, even for those at risk of dropping out. De Chaisemartin et al. (2020) find no effect of three SMS per week during a period of 7 months directed to parents of a low-income family in France to increase interactions with their children on children abilities.

Consequently, neither the result of this field experiment nor the recent empirical evidence is in favor of the use of SMS by public institutions to communicate more effectively about their services to external individuals.

7 The covariates are introduced as dummies that deviate from their means, as suggested by Athey and Imbens (2017). By doing so, the estimates of the intercept are in line with the situation in which there are no control variables although their interpretation is different.

8 I am not able to determine whether or not the youths opened their SMS, but according to the 2018 annual barometer of the marketing mobile association France, about 95\% of commercial SMS were opened. According to Esendex, $100 \%$ of those aged 18-24 years opened their SMS in 2018 when a name was provided. Overall, the average treatment effects on the treated (ATT) should be similar to the ITT. 


\subsection{The effect of SMS according to language style}

Although SMS have no overall impact, it is still possible that the effect is differentiated according to the language style adopted in the messages. I ran Eq. (1) by splitting the treatment SMS into two groups, as described in Section 3, to bring answers to the second question asked in the Introduction section.

Results are shown in Panel B of Table 3, the columns of which are similar to those of Panel A. The results, which are again very stable across specifications, show the absence of statistically significant effects of SMS on the probability of going to an ML agency, whatever the language style (formal/informal)adopted. Panel B of Table F1 in Online Appendix F shows the same results with probit estimates.

Panel B of Table 3 further reports the $p$-values of Student tests of equality between the estimates of formal SMS and informal SMS. The two types of treatment do not differ statistically from each other or barely differ at the $90 \%$ confidence level. It is still interesting to note that the point estimates are very close to zero for formal SMS, while they are around $-1.3 \mathrm{pp}$ for informal SMS. This result might suggest that the informal tone is negatively perceived by young people when the SMS come from a public institution.

The informal tone within the SMS of Treatment 2 is mostly captured using the French subject pronoun " $t u$ " instead of "vous" in Treatment 1 . While they are both translated into the pronoun " $y o u$ " in English, they do not have the same meaning in French. Indeed, " $t u$ " is mostly used in private correspondences, whereas "vous" is mostly used in nonprivate or public correspondences. Yet, Pires (2004) explains that public institutions sometimes use the pronoun " $t u$ " for public information disclosures to include everyone privately. This strategy aims for individuals to incorporate the public messages in their individual decisions. However, it seems that the use of this informal tone by public institutions in the presented SMS failed the field experiment test.

\subsection{Alternative specifications}

The effect of the SMS on agency direction might differ on different dimensions. In order to analyze potential heterogeneous effects, I provide estimates of $\beta$ by allowing interactions between the SMS treatment variables and characteristics included in the set of control variables. Tables G1, G3, and G5 in Online Appendix G show the estimates according to individual, agency, and location characteristics, respectively. Estimates related to treatment groups are mostly nonsignificant across these dimensions. Tables G2, G4, and G6 in Online Appendix G further confirm the nonsignificant effects across these characteristics by showing the bootstrap $p$-values and randomization inference $p$-values in Panel A and Panel B, respectively.

I also look at the evolution of the agency take-up rate over time with respect to the type of treatment group the youths were allocated to. Figures $\mathrm{H} 1$ and $\mathrm{H} 2$ in Online Appendix $\mathrm{H}$ show the survival curves of the treatment groups overall and by month, respectively, but there is no difference between the groups that received SMS and that did not. I then turn to a proportional hazard model estimated with a Cox regression, controlling for time and individual characteristics. Table I1 and Figure I1 in Appendix I also show no effect from the treatments. Although potential dynamic selection can appear over time, it seems that none of the treatment SMS are 
statistically different from the case of no SMS in directing young people toward public assistance agencies.

\section{Concluding Remarks}

Directing young dropouts through low-cost SMS has little chance of triggering the expected behavior since the field experiment presented in this paper shows no effect of SMS on enrollment in public agencies delivering mainly job search assistance. As noted by Babcock et al. (2012), information transmitted to job seekers "should be simple and personalized" and "the presentation and context of this information can potentially invoke frames of loss or gain". While the former point can be considered satisfied in this experiment as the SMS were quite concise, written in a simple language, and individualized to some youth and agency characteristics, there is room for improvement given the latter point; however, there are inherent difficulties considering the nature of SMS.

Insights from behavioral economics indicate that the psychological and external barriers encountered by young job seekers may be too deep, and so their expectations are misaligned with reality. Some may overestimate their propensity to exit from a nonemployment situation and find a sustainable alternative by themselves. ${ }^{9}$ Conversely, young dropouts may underestimate their own abilities and present an external locus of control and/or display a serious lack of confidence in themselves. As young dropouts may be located beyond the reach of public authorities, they may even feel abandoned and locked into their nonemployment situation. This is where public assistance would be the most needed for this population. Neumark and Rothstein (2005) even show that school-to-work programs targeting students who are less likely to pursue education in the United States may have positive effects on postsecondary education and employment, especially for men. Caliendo and Schmidl (2016) show more contrasting results depending on the type of active labor market policies supplied by public agencies in European countries. Yet, evidence on information campaigns to attract this population is still scarce in the academic literature, and this paper initiates a first step.

Future information campaigns designed by public institutions should try to incorporate elements that clearly state the gains and losses that young dropouts might face when choosing options over a default. The language style adopted in the information campaign and its potential connotation associated with the type of institution might therefore be correlated to the specificity of information. Information related to gains may be framed or displayed in a way that differs from information related to losses. More research in this direction is needed to provide information to young dropouts in a salient way if one wants to increase participation in labor market policies. This point implicitly assumes that information on agencies' performances is available. Small-scale tests on a preselected panel of young dropouts and cooperation among policymakers, economists, psychologists, and behavioral scientists should be at play to design and evaluate future information campaigns.

9 Spinnewijn (2015) shows that $80 \%$ of US job seekers underestimated their unemployment duration. Mueller et al. (2018) show that about $10 \%$ of the incidence of long-term unemployment can be attributable to optimistic bias in the jobfinding rate. 


\section{Declarations}

\section{Availability of data and material}

The data sets used and/or analyzed during the current study are available from the corresponding author on reasonable request.

The associated programs used to generate the results in the current study are based on Python Jupyter Notebooks, which are available from the corresponding author on reasonable request.

\section{Competing interests}

The author declares that he has no competing interests.

\section{Funding}

This project was granted by the chair of Sécurisation des Parcours Professionnels and administratively supported by the Institut Louis Bachelier (grant: SPP-2019-PR28).

\section{Acknowledgments}

This project was possible thanks to the former Ministerial Delegation of Missions Locales (DMML) for their administrative support. I also thank the Ministry of the Army (DSNJ) and the Ministry of Labor (DARES) for data access and legal support. This project was conducted under the patronage of the Chaire, Sécurisation des parcours professionnels (chaire-securisation.fr), whose partners are the Ministry of Labor, Pôle emploi (public employment service), Unédic (public unemployment insurance), Alpha group (consultancy firms specialized in labor relations), Sciences Po, and Centre de recherche en économie et statistique (CREST) École nationale de la statistique et l'administration économique (ENSAE). The steering committee of the Chair, composed of representatives of these institutions, approved this experiment without imposing any constraint on the design proposed by the author.

\section{References}

Abel, Martin; Rulof Burger; Eliana Carranza; Patrizio Piraino (2019): Bridging the Intention-Behavior Gap? The Effect of Plan-Making Prompts on Job Search and Employment. American Economic Journal 11(2), 284-301.

Altmann, Steffen; Armin Falk; Simon Jäger; Florian Zimmermann (2018): Learning About Job Search: A Field Experiment with Job Seekers in Germany. Journal of Public Economics 164, 33-49.

Athey, Suzan; Guido W. Imbens (2017): The Econometrics of Randomized Experiments. Handbook of Economic Field Experiment 1, 73-140.

Armour, Philip (2018): The Role of Information in Disability Insurance Application: An Analysis of the Social Security Statement Phase-In. American Economic Journal 10(3), 1-41.

Babcock, Linda; William J. Congdon; Lawrence F. Katz; Sendhil Mulhainathan (2012): Notes on Behavioral Economics and Labor Market Policy. IZA Journal of Labor Policy 1(1), 1-4.

Barr, Andrew; Sarah Turner (2018): A Letter and Encouragement: Does Information Increase Post-secondary Enrollment of UI Recipients? American Economic Journal 10(3), 42-68.

Belot, Michèle; Philipp Kircher; Paul Muller (2019): Providing Advice to Jobseekers at Low Cost: An Experimental Study on Online Advice. The Review of Economic Studies 86(4), 1411-1447.

Berkes, Jan; Frauke Peter; C. Katharina Spiess; Felix Weinhardt (2019): Information Provision and Postgraduate Studies. IZA Discussion Paper Series No. 12735, 40.

Bettinger, Eric P.; Bridget Terry Long; Philip Oreopoulos; Lisa Sanbonmatsu (2012): The Role of Application Assistance and Information in College Decisions: Results from the H\&R Block Fafsa Experiment. The Quarterly Journal of Economics 127(3), 1205-1242.

Bhargava, Saurabh; Dayanand Manoli (2015): Psychological Frictions and the Incomplete Take-Up of Social Benefits: Evidence from an IRS Field Experiment. American Economic Review 105(11), 3489-3529.

Caliendo, Marco; Ricarda Schmidl (2016): Youth Unemployment and Active Labor Market Policies in Europe. IZA Journal of Labor Policy 5(1), 1-30.

Castleman, Benjamin L.; Lindsay C. Page (2015): Summer Nudging: Can Personalized Text Messages and Peer Mentor Outreach Increase College Going Among Low-income High School Graduates? Journal of Economic Behavior \& Organization 115, 144-160.

Cour des Comptes (2016): La Journée Défense et Citoyenneté. Technical Report, Cour des comptes. Communication à la Commission des finances du Sénat.

de Chaisemartin, Clément; Charlotte Combier; Quentin Daviot; Marc Gurgand; Sophie Kern (2020): Inégaux dès le berceau: des SMS pour améliorer les interactions langagières entre parents et enfants de familles défavorisées?. Note IPP 59. 
Ehrenreich, Samuel E.; Marion K. Underwood; Robert A. Ackerman (2014): Adolescents' Text Message Communication and Growth in Antisocial Behavior across the First Year of High School. Journal of Abnormal Child Psychology 42(2), 251-264.

Finkelstein, Amy; Matthew J. Notowidigdo (2019): Take-Up and Targeting: Experimental Evidence from SNAP. The Quarterly Journal of Economics 134(3), 1505-1556.

Fryer, Roland G. (2016): Information, Non-financial Incentives, and Student Achievement: Evidence from a Text Messaging Experiment. Journal of Public Economics 144, 109-121.

Gerber, Alan S.; Donald P. Green; Christopher W. Larimer (2008): Social Pressure and Voter Turnout: Evidence from a Large-Scale Field Experiment. American Political Science Review 102(1), 33-48.

Goldzahl, Léontine; Guillaume Hollard; Florence Jusot (2018): Increasing Breast-cancer Screening Uptake: A Randomized Controlled Experiment. Journal of Health Economics 58, 228-252.

Graham, Jacqueline B (2013): Impacts of Text Messaging on Adolescents' Communication Skills: School Social Workers' Perceptions. Master of Social Work Clinical Research Papers 63.

Hudson, Heather K.; Kadi R. Bliss; Joyce V. Fetro (2012): Effects of Text Messaging on College Students' Perceptions of Personal Health. Health Educator 44(1), 28-35.

Jones, Graham M.; Bambi B. Schieffelin (2009): Talking Text and Talking Back: "My BFF Jill” from Boob Tube to YouTube. Journal of Computer-Mediated Communication 14(4), 1050-1079.

Liebman, Jeffrey B.; Erzo F. P. Luttmer (2015): Would People Behave Differently If They Better Understood Social Security? Evidence from a Field Experiment. American Economic Journal: Economic Policy 7(1), 275-299.

Ling, Rich (2010): Texting as a Life Phase Medium. Journal of Computer-Mediated Communication 15(2), 277-292.

Ling, Rich; Noamie S. Baron (2016): Text Messaging and IM: Linguistic Comparison of American College Data. Journal of Language and Social Psychology 26(3), 291-298.

Mason, Michael; Bolanle Ola; Nikola Zaharakis; Jing Zhang (2015): Text Messaging Interventions for Adolescent and Young Adult Substance Use: A Meta-Analysis. Prevention Science 16(2), 181-188.

Mueller, Andreas; Johannes Spinnewijn; Giorgio Topa (2018): Job Seekers' Perceptions and Employment Prospects: Heterogeneity, Duration Dependence and Bias. NBER Working Paper Series 25294.

Neumark, David; Donna Rothstein (2005): Do School-to-Work Programs Help the "Forgotten-half"?. NBER Working Paper Series 11636.

Oreopoulos, Philip; Ryan Dunn (2013): Information and College Access: Evidence from a Randomized Field Experiment. The Scandinavian Journal of Economics 115(1), 3-26.

Oreopoulos, Philip; Uros Petronijevic (2019): The Remarkable Unresponsiveness of College Students to Nudging and What We Can Learn from It. IZA Discussion Paper Series No. 12460.

Oreopoulos, Philip; Uros Petronijevic; Christine Logel; Graham Beattie (2020): Improving Non-academic Student Outcomes Using Online and Text-message Coaching. Journal of Economic Behavior \& Organization 171, 342-360.

Pires, Mat (2004): Usages et stratégies de tutoiement dans l'écrit public. Langage et société (108), 27-56.

Rettie, Ruth; Ursula Grandcolas; Bethan Deakins (2005): Text Message Advertising: Response Rates and Branding Effects. Journal of Targeting, Measurement and Analysis for Marketing 13(4), 304-312.

Riordan, Monica A.; Roger J. Kreuz (2010): Cues in Computer-mediated Communication: A Corpus Analysis. Computers in Human Behavior 26(6): 1806-1817.

Spinnewijn, Johannes (2015): Unemployed but Optimistic: Optimal Insurance Design with Biased Beliefs. Journal of the European Economic Association 13(1), 130-167. 